\title{
DEGRADAÇÃO DE CORANTES MODELO POR FOTÓLISE
}

\author{
Amanda Santos de Lima ${ }^{1}$ \\ Mariana de Souza Sikora ${ }^{2}$
}

\begin{abstract}
RESUMO
Neste trabalho investigou-se a degradação de corantes modelo por fotólise. A fotólise é um processo fotoquímico, no qual uma determinada reação é promovida pela absorção de radiação eletromagnética. No presente trabalho investigou-se a reação de degradação dos seguintes corantes: azul de metileno, azul de bromotimol, alaranjado de metila e violeta de genciana. Os resultados foram analisados quanto a cinética correspondente. Observou-se que o azul de bromotimol e o violeta de genciana apresentam descoloração completa em 50 min de exposição à luz UV. O alaranjado de metila e o azul de metileno não são completamente degradados neste tempo. Em relação à cinética de degradação observou-se que o alaranjado de metila e o azul de bromotimol apresentam uma cinética de primeira ordem. Já os demais corantes estudados apresentam ordens mistas, provavelmente devido à formação de compostos intermediários que interferem na absorbância do composto primário. Os resultados mostram que a fotólise é um método eficiente na degradação de compostos, sendo possível aplicá-la na degradação de efluentes reais.
\end{abstract}

PALAVRAS-CHAVE: Fotólise. POA. Corantes.

\section{COLOURS OF DECAY MODEL BY PHOTOLYSIS}

\begin{abstract}
In this work it was investigated the degradation of model dyes by photolysis. Photolysis is a photochemical process, in which a particular reaction is promoted by absorption of electromagnetic radiation. In this study it was investigated the degradation reaction of the following dyes: methylene blue, bromothymol blue, methyl orange and gentian violet. Results were analyzed as the corresponding kinetics. It was observed that bromothymol blue and gentian violet are completely discolourated in $50 \mathrm{~min}$ of exposure to UV light. The methyl orange and methylene blue are not completely degraded at this time. Regarding the degradation kinetics was observed that the methyl orange and bromothymol blue exhibit a first-order kinetics. The other dyes studied have mixed kinetics orders, probably due to the formation of intermediate compounds that interfere with the absorbance of the primary compound. The results show that the photolysis is an efficient method in the degradation of compounds, it being possible to apply it in the degradation of actual effluents.
\end{abstract}

KEYWORDS: Photolysis. AOP. Dyes.

\footnotetext{
${ }^{1}$ Graduanda em Química, Universidade Tecnológica Federal do Paraná - UTFPR, Campus Pato Branco. E-mail: amandasnts@hotmail.com.

2 Bacharel e Licenciada em Química (UNICENTRO), Doutora em Ciências, Área Físico-Química (UFSCar). Professora na Universidade Tecnológica Federal do Paraná - UTFPR. E-mail: marianasikora@utfpr.edu.br
} 


\section{Periódica Eletranica \\ Fórum Ambiental}

da Alta Paulista

\section{COLORES DE CARIES MODELO POR FOTOLISIS}

\section{RESUMEN}

En este trabajo se investigó la degradación del colorante modelo por fotólisis. Fotólisis es un proceso fotoquímico, en el que una reacción particular es promovido por la absorción de radiación electromagnética. En este estudio se investigó la reacción de degradación de los siguientes colorantes: azul de metileno, azul de bromotimol, naranja de metilo y violeta de genciana. Los resultados se analizaron como la cinética correspondientes. Se observó que la decoloración del bromotimol azul y de el violeta de genciana és completa en 50 minutos de exposición a la luz UV. EI naranja de metilo y azul de metileno no se degradan completamente en este momento. En cuanto a la cinética de degradación se observó que el naranja de metilo y azul de bromotimol exhiben una cinética de primer orden. Dado que los otros colorantes han estudiado las órdenes mezcladas, probablemente debido a la formación de compuestos intermedios que interfieren con la absorbancia del compuesto primario. Los resultados muestran que la fotólisis es un método eficiente en la degradación de compuestos, siendo posible aplicarlo en la degradación de el efluente real.

PALABRAS-CLAVE: Fotólisis. POA. Colorantes.

\section{INTRODUÇÃO}

A preocupação com o meio ambiente aumenta a cada dia. Isto se deve a uma conscientização global gerada por uma série de estudos e campanhas realizadas principalmente por organizações não governamentais ("Greenpeace International Home | Greenpeace International", [s.d.], "WWF Brasil -", [s.d.]).

Dentro os setores mais poluidores encontra-se o setor industrial devido aos diversos efluentes produzidos. Segundo a Norma Brasileira - NBR 9800/1987, efluente líquido industrial é o despejo líquido proveniente do estabelecimento industrial, compreendendo emanações de processo industrial, águas de refrigeração poluídas, águas pluviais poluídas e esgoto doméstico. Muitas vezes eles não são tratados devidamente e são descartados em rios de forma inadequada.

Para tal problema várias metodologias foram testadas. Dentre elas destacase a degradação de efluentes por Processos Oxidativos Avançados (POA's). Os POA's se apresentam como uma alternativa interessante da descontaminação e/ou degradação de efluentes com poluentes químicos ou biológicos tóxicos (TEIXEIRA; JARDIM, 2004).

Os POA's consistem de uma série de processos tais como fotocatálise (FUJISHIMA; RAO; TRYK, 2000; KHAN; AL-SHAHRY; INGLER, 2002), fotólise (MURUGANANDHAM, 2004), processos fenton e foto fenton (PUPO NOGUEIRA et 
al., 2007) que visam a descontaminação por meio da mineralização de poluentes à substâncias inertes tais como compostos inorgânicos, $\mathrm{CO}_{2}$ e $\mathrm{H}_{2} \mathrm{O}$.

Neste trabalho investigou-se a degradação de corantes modelos por fotólise. A fotólise é a quebra de uma molécula (lise) através da absorção de fótons. As reações químicas que ocorrem através da absorção de radiação eletromagnética são chamadas de reações fotoquímicas (MCQUARRIE; SIMON, 1997). Existem diversos tipos de processos fotoquímicos, como a fotoisomerização, fotodimerização e a fotodissociação ou fotólise.

Uma maneira de se estudar a degradação de efluentes industriais é realizar um estudo prévio envolvendo compostos modelos que apresentam grupos funcionais conhecidos para que depois o estudo possa ser extrapolado para efluentes reais, os quais apresentam compostos e comportamentos desconhecidos. Desta forma, neste trabalho estudou-se a viabilidade do uso da fotólise para 0 tratamento de efluentes a partir de alguns corantes modelos, sendo eles, o alaranjado de metila, o azul de metileno, o violeta de genciana e o azul de bromotimol.

\subsection{OBJETIVOS}

Neste trabalho estudou-se a degradação de corantes modelo através do estudo da fotólise destes compostos. Buscou-se investigar a viabilidade da degradação de corantes através de processos fotoquímicos.

\section{METODOLOGIA}

Para os experimentos de fotólise utilizou-se uma black box, um reator encamisado de $150 \mathrm{~mL}$ com uma lâmpada UV de $150 \mathrm{~W}$, a reação de degradação foi realizada utilizando agitação mecânica a fim de se eliminar possíveis efeitos difusionais. Todos os corantes foram estudados usando-se uma concentração de 50 $\mathrm{mg} \mathrm{L}^{-1}$, a temperatura ambiente foi mantida constante através de um fluxo externo de água corrente.

A fotólise foi investigada através da quantificação da variação na absorbância do corante em função do tempo de degradação. Alíquotas foram tiradas 
nos tempos $t=\{0,10,20,30$ e 50\} $\min$. Após a análise no Espectrofotômetro Thermo Fisher scientific - evolution 60s, os resultados foram modelados de acordo com a ordem cinética correspondente.

\section{RESULTADOS}

A Figura 1 apresenta os espectros de absorbância para as reações de degradação dos corantes (a) azul de bromotimol e (b) alaranjado de metila. Como pode-se notar, para o azul de bromotimol há o desaparecimento do pico característico do grupo cromóforo em 50 min de reação de degradação. Já para o alaranjado de metila, apesar de haver uma descoloração significativa, ainda existe uma quantidade significativa do composto ao final de 50 min de reação.

Figura 1 - Espectros de Absorbância para os corantes (a) azul de bromotimol e (b) alaranjado de metila.

(a)

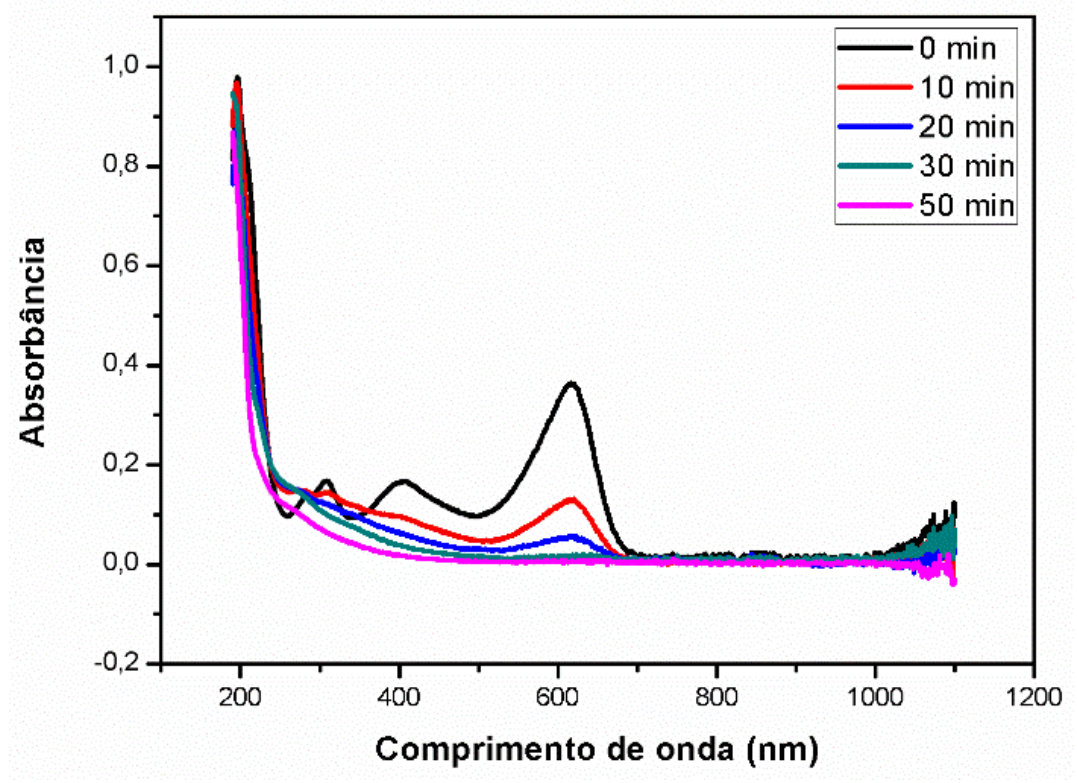

(b) 


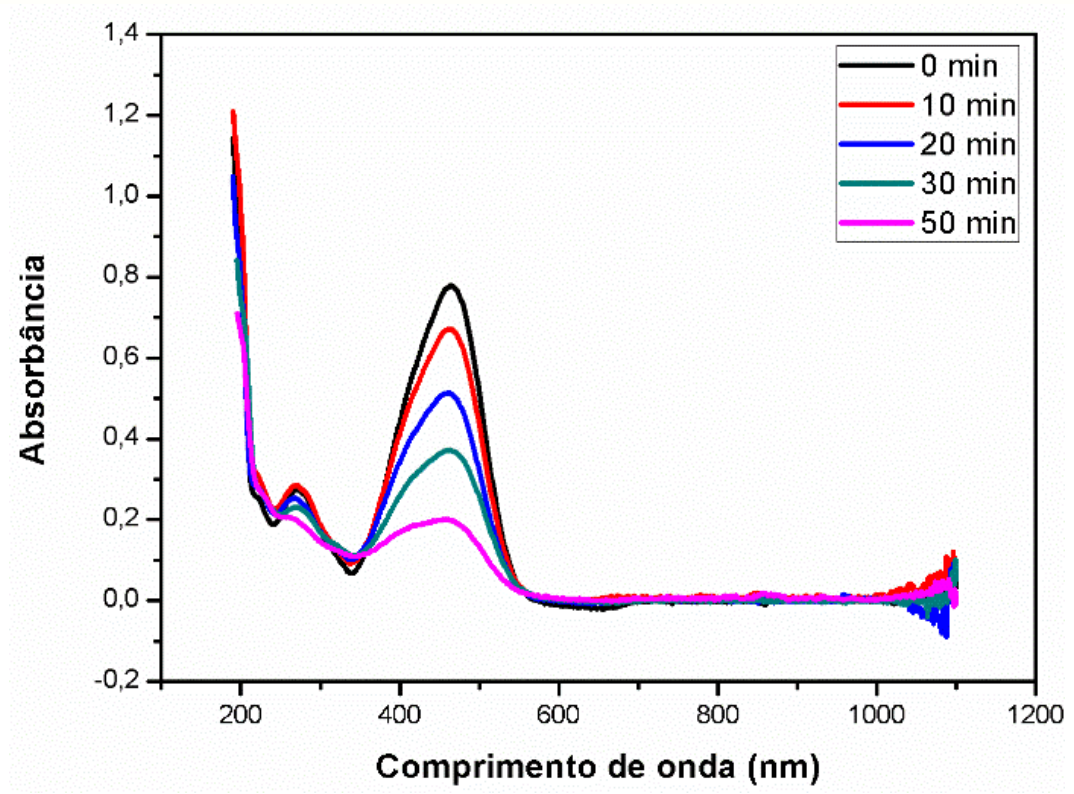

Fonte: Autor, 2015

A descoloração dos corantes, é perceptível a olho nú, como pode ser observado na Figura 2. Como é comprovado pelo espectro de absorbância dos corantes, o azul de bromotimol é mais sensível à exposição à luz UV, pois ao final de 50 min está completamente degradado.

Figura 2- Fotos mostrando a descoloração dos corantes (a) azul de bromotimol e (b) alaranjado de metila em função do tempo de fotólise.

(a)

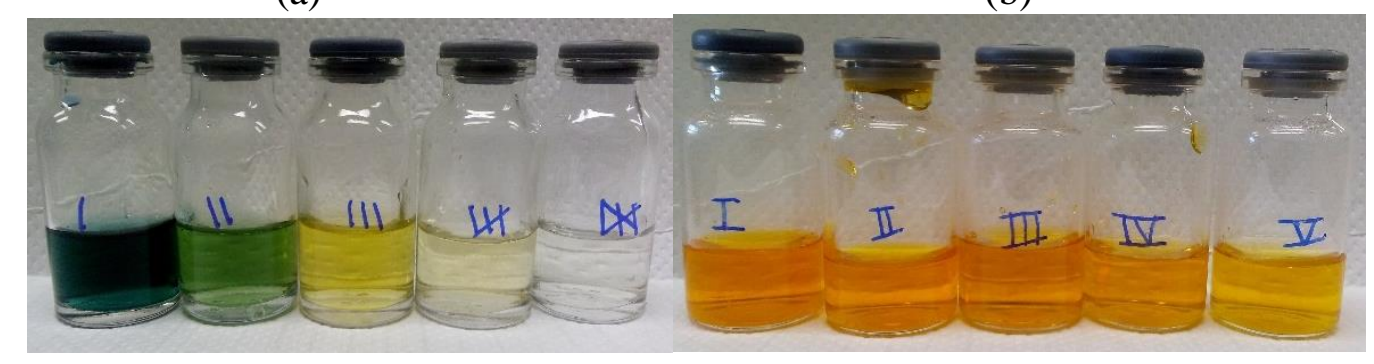

Fonte: Autor, 2015

(b)

A Figura 3 apresenta os espectros de absorbância para (a) o violeta de genciana e (b) azul de metileno. Na Já para o azul de metileno, pode-se observar que há uma intensificação da coloração do corante em função do tempo de fotólise. Isto se deve provavelmente à conversão da molécula do corante em compostos intermediários antes do processo de mineralização, o que pode acontecer com 
frequência quando se trabalha com a degradação fotoquímica de efluentes industriais reais.

Figura 4 apresentam-se as fotos das alíquotas retiradas em vários tempos de degradação. Como pode-se notar a solução de violeta de genciana retirada após 50 min de reação parece incolor indicando a completa degradação do corante durante este tempo de reação fotoquímica. O espectro de absorbância referente à esta amostra confirma o decréscimo da concentração do corante em função do tempo. 
Figura 3 - Espectros de Absorbância para (a) violeta de genciana e (b) azul de metileno em diferentes tempos de degradação.

(a)

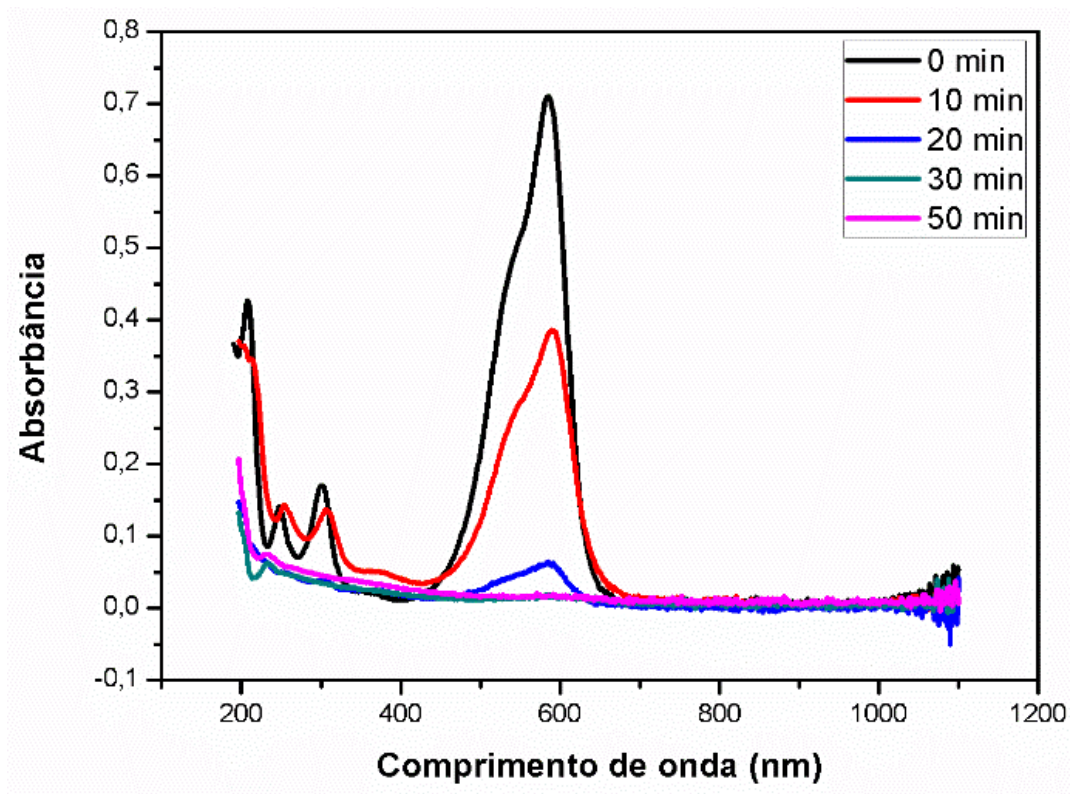

(b)

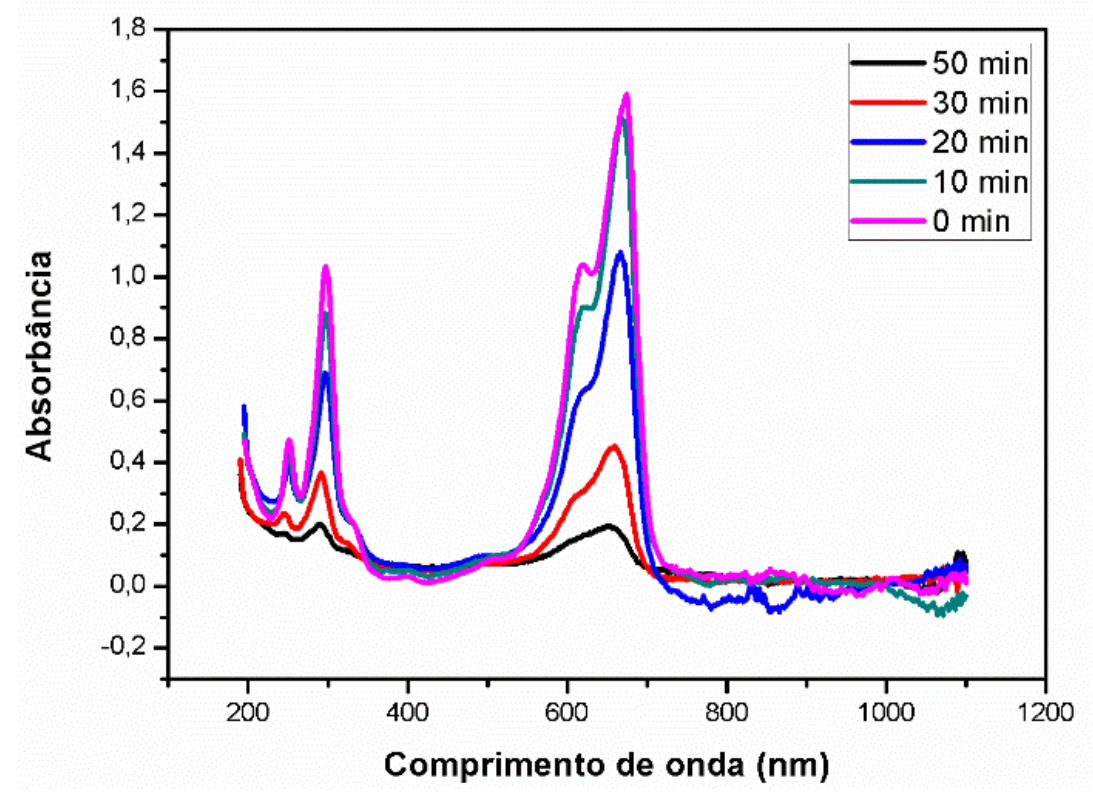

Fonte: Autor, 2015

Já para o azul de metileno, pode-se observar que há uma intensificação da coloração do corante em função do tempo de fotólise. Isto se deve provavelmente à conversão da molécula do corante em compostos intermediários antes do processo de mineralização, o que pode acontecer com frequência quando se trabalha com a degradação fotoquímica de efluentes industriais reais. 
Figura 4 - Fotos mostrando a descoloração dos corantes (a) violeta de genciana e (b) azul de metileno em função do tempo de fotólise.

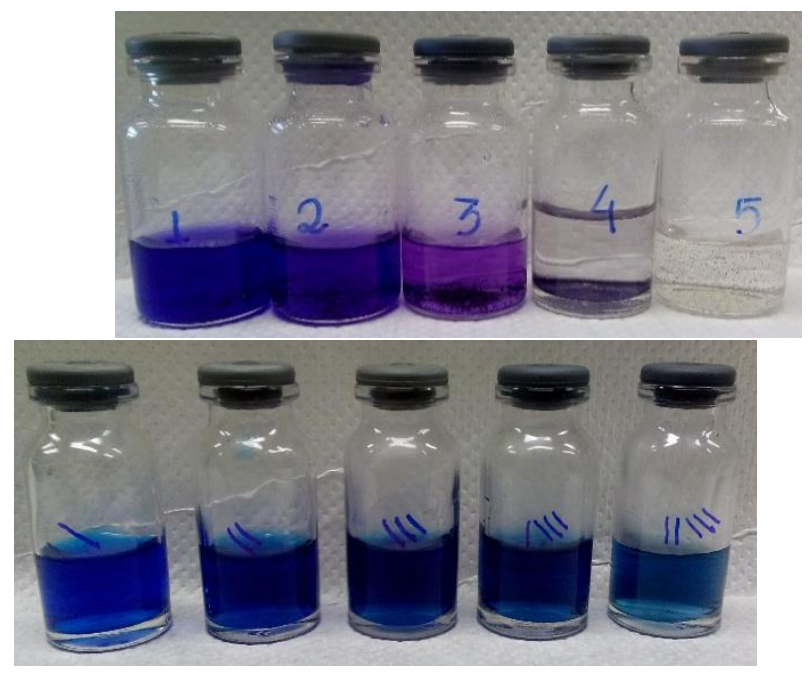

Fonte: Autor, 2015

Reações de degradação que seguem uma cinética de primeira ordem podem ser modeladas pela lei de velocidade integrada dada por:

$$
\ln [A]=\ln [A]_{0}-k t
$$

Onde $[A]$ refere-se a concentração da espécie $\mathrm{A}$, que neste estudo representa a concentração dos corantes investigados, em um determinado tempo $t \mathrm{e}$ $[A]_{0}$ corresponde à concentração inicial do corante, $k$ é a constante de velocidade da reação, quanto maior o seu valor, mais rápida é a velocidade de degradação do corante. De acordo com a lei de Beer-Lambert, a absorbância é proporcional à concentração da espécie analisada, sendo assim, pode-se estudar a cinética da reação modelando os dados de absorbância em função do tempo.

Para a análise cinética da reação de degradação dos corantes utilizou-se o comprimento de onda relacionado ao máximo de absorbância. Os resultados foram analisados quanto ao tempo de descoloração dos corantes utilizados. Na Figura 5 são apresentados em (a) a variação da absorbância normalizada em função do tempo para todos os corantes e (b) $\ln \left(\frac{A b s}{A b s_{0}}\right)$ em função do tempo.

O gráfico (a) expressa a modelagem da reação considerando uma cinética de ordem zero. Em (b) considera-se a modelagem para uma reação de primeira ordem. 
O azul de bromotimol e o alaranjado de metila apresentam uma cinética de primeira ordem com constantes de velocidade de $0,102 \mathrm{~s}^{-1}$ e $0,028 \mathrm{~s}^{-1}$, respectivamente. Já o azul de metileno e o violeta de genciana apresentam ordens mistas, provavelmente devido à formação de compostos intermediários que promovem o deslocamento ou distorção da banda de absorção do corante, assim a leitura da absorbância não corresponde somente ao corante, mas também aos intermediários de reação.

Figura 5 - Curvas cinéticas para a reação de degradação dos corantes. (a) Modelagem de ordem zero e (b) Modelagem de primeira ordem

(a)

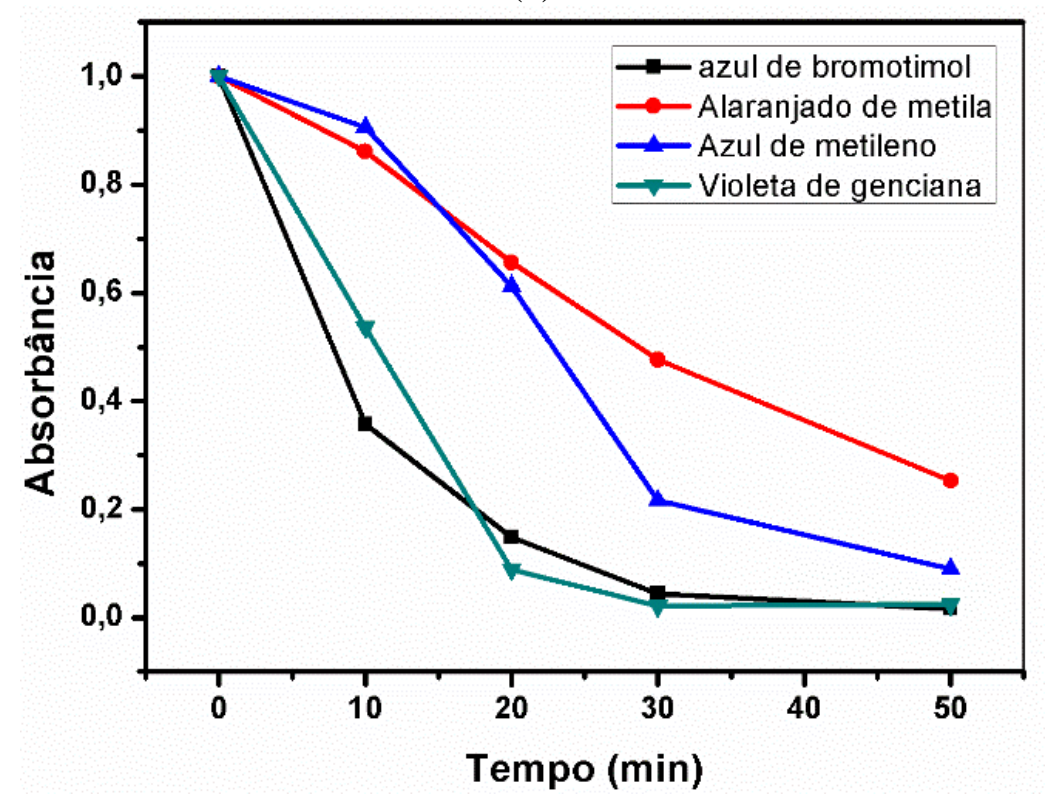

(b) 


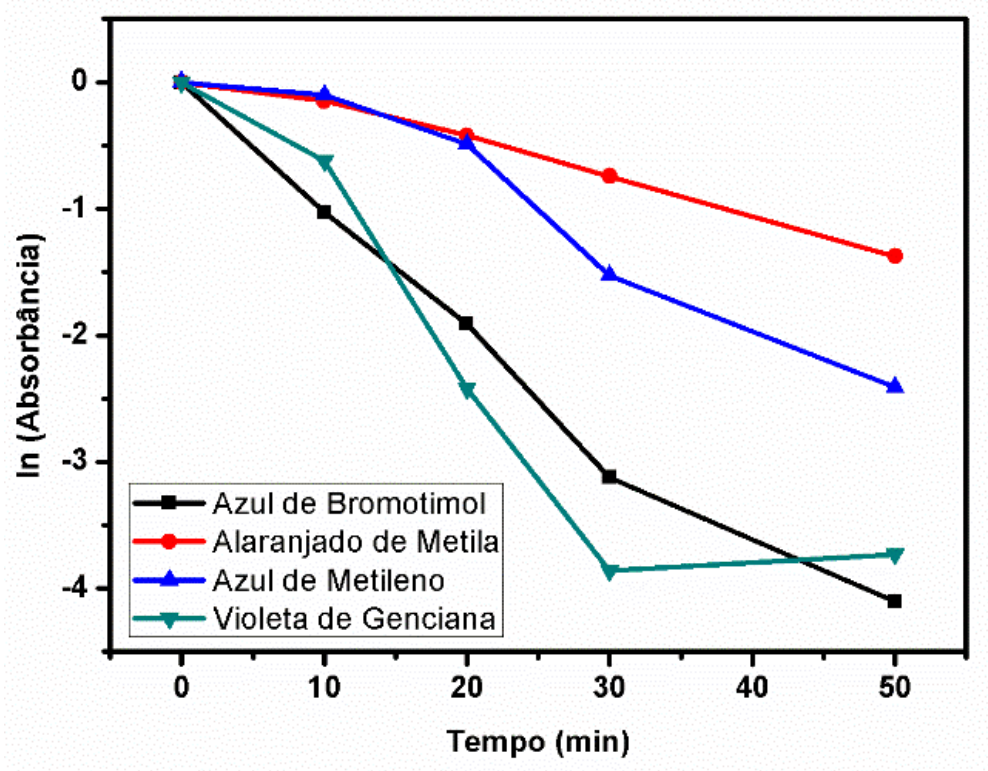

Fonte: Autor, 2015

Todos os corantes sofreram fotodissociação, sendo que a reação de fotólise foi mais efetiva para os corantes azul de bromotimol e violeta de genciana. Sendo assim, o processo fotoquímico estudado mostrou-se eficaz para a degradação de compostos com potencial toxicidade e pode ser aplicado para a degradação de efluentes reais.

\section{CONCLUSÃO}

Neste trabalho estudou-se a eficiência da reação de fotólise para a degradação de corantes modelo. Todos os corantes estudados sofreram degradação durante a reação fotoquímica, sendo que o azul de bromotimol e o violeta de genciana apresentaram descoloração completa ao final de $50 \mathrm{~min}$ de reação fotoquímica. Em relação à cinética de degradação observou-se que o alaranjado de metila e o azul de bromotimol apresentam uma cinética de primeira ordem. Já os demais corantes estudados apresentam ordens mistas, provavelmente devido à formação de compostos intermediários que interferem na absorbância do composto primário. Os resultados mostram que a fotólise é um método eficiente na degradação de corantes. Sendo assim, considera-se que o processo de fotólise é um método eficiente para a degradação de efluentes industriais reais. 


\section{REFERÊNCIAS}

FUJISHIMA, A.; RAO, T. N.; TRYK, D. A. Titanium dioxide photocatalysis. Journal of

Photochemistry and Photobiology C: Photochemistry Reviews, v. 1, n. 1, p. 1-21, 2000.

Greenpeace International Home | Greenpeace International. Disponível em:

$<$ http://www.greenpeace.org/international/en/>.

KHAN, S. U. M.; AL-SHAHRY, M.; INGLER, W. B. Efficient photochemical water splitting by a chemically modified n-TiO2 2. Science, v. 297, n. 5590, p. 2243-2245, 2002.

MCQUARRIE, D. A.; SIMON, J. D. Physical Chemistry: A Molecular Approach. [s.I: s.n.].

MURUGANANDHAM, M. Photochemical oxidation of reactive azo dye with UV-H2O2 process. Dyes and Pigments, v. 62, n. 3, p. 269-275, set. 2004.

PUPO NOGUEIRA, R. F. et al. Fundamentos e aplicações ambientais dos processos Fenton e fotoFenton. Quimica Nova, v. 30, n. 2, p. 400-408, 2007.

TEIXEIRA, C. P. S. B.; JARDIM, W. F. Processos Oxidativos Avançados Caderno Tematico 3. 2004.

WWF Brasil -. Disponível em: <http://www.wwf.org.br/>. 